\title{
Hypermnesia for pictures but not for concrete or abstract words
}

\author{
A. DANIEL YARMEY \\ University of Guelph, Guelph, Ontario, Canada N1G 2W1
}

\begin{abstract}
Subjects were presented with pictures, concrete nouns, or abstract nouns for a single learning trial followed by three forced recall trials. Performance was found to improve with repeated recall for pictures (hypermnesic effect) but not for words. Memory of pictures was superior to recall of concrete nouns, which in turn was superior to recall of abstract nouns. The results are interpreted as supporting an hypothesis that qualitative differences in imagery, and not the dual encoding theory, account for the picture superiority effect. The dual encoding theory, however, can and does predict differences in word abstractness/concreteness recall.
\end{abstract}

Over the last few years, a large amount of evidence has been gathered which shows that memory for pictures is generally superior to recall for their concrete noun labels (Paivio \& Csapo, 1973; Paivio, Rogers, \& Smythe, $1968)$ and that both pictures and concrete nouns are superior in recall to abstract nouns (Paivio \& Csapo, 1969). Paivio (1971) has explained these differences by postulating that pictures are more likely to be coded and stored in memory as both imaginal representations and their verbal labels. Concrete nouns may also be encoded both as verbal codes and as visual codes, but there is a lower probability for imagery representations than verbal codes. Abstract nouns, however, are not likely to elicit pictorial codes and are stored in memory only as verbal representations. The dual coding theory assumes that recall is facilitated by and is greater for stimulus materials that have both verbal and imaginal codes available as mediators. However, studies by Nelson and Brooks (1973) and Yarmey (1974) on paired-associate learning of pictures and words indicate that verbal labeling of pictures may not be implicit or necessary for associative recall. The general superiority of pictures over words in learning may not be a function of dual encoding. This conclusion is supported further by a recent study by Erdelyi and Becker (1974). Pictures were shown to be superior to their word labels in multiple-trial recall following a single learning trial, but the performance differences were of a particular nature. A hypermnesic function, in which performance improved over repeated free recalls, was found for pictures but not for words. Erdelyi and Becker (1974) concluded that the picture-word differences may be, but

This research was supported by a grant from the National Research Council of Canada (A0288). The manuscript was written while the author was a Visiting Associate Professor at the University of Tennessee. I wish to thank George R. Andreoff for his help in gathering the data and analysis of the results. Requests for reprints should be sent to A. Daniel Yarmey, Department of Psychology, University of Guelph, Guelph, Ontario, Canada N1G 2W1. are not necessarily, a function of a dual coding memory system. The greater availability of both imaginal and verbal codes may account for the positive increment in performance over repeated trials for pictures. But, concrete nouns also elicit memory images as associative reactions, as well as verbal associative meanings, and the hypermnesic function was not present for words. Consequently, Erdelyi and Becker (1974) were reluctant to attribute the differential performance of pictures and their word labels to a dual coding hypothesis.

Paivio (1971) points out, however, that pictures and words may also be distinguished by their respective levels of concreteness. Although both are highly concrete by definition, there may be qualitative differences in their referent imagery. Paivio (1971) defines concreteness "... in terms of the ease with which the stimulus evokes an image of an object or objects, or simply as the 'picturability' of a stimulus ..." (p. 59). Objects or their pictorial representations are able to directly elicit perceptual images, whereas concrete nouns must derive their imagery through mediated associative reactions. The imagery elicited to pictures is relatively simple and direct, but the imagery elicited to concrete nouns will vary depending upon the person's past experiences with that object or its pictorial representations and the verbal label. Consequently, concrete words may elicit single or multiple images as associative reactions which will vary in their relative availability as mediators for recall. The concreteness dimension of stimulus meaning is further differentiated at the imaginal symbolic level. Abstract nouns and concrete nouns both elicit verbal associative meanings, but only concrete nouns are likely to elicit images as associative reactions.

It is conceivable that the dual coding theory may predict and explain differences in learning at the word abstractness/word concreteness level of meaning but not at the picture/concrete word level of symbolic meaning. In order to test this hypothesis, the present study attempted to replicate the results of Erdelyi and Becker (1974) and, in addition, tested whether or not the lack 
of a hypermnesic effect for words is apparent for both high-imagery concrete nouns and low-imagery abstract nouns. If pictures, but not concrete words or abstract words, show a hypermnesic memory function, these results would add further support to the hypothesis that differences in qualitative imagery and not dual encoding account for the superiority in memory for pictures over words. Furthermore, it was hypothesized from the dual encoding theory that concrete nouns, because of their higher rated-imagery values, would be superior to abstract nouns over multiple recalls.

\section{METHOD}

\section{Subjects}

Thirty undergraduate psychology students volunteered to participate as subjects. All subjects were randomly assigned in order of their appearance at the laboratory to three separate groups of 10 subjects each.

\section{Stimuli}

Sixty pictures were chosen from a pool of drawings prepared by Csapo (Note 1) on which normative data are available for latency, consistency of labeling, and Thorndike-Lorge (1944) word frequency scores. The noun labels of each picture are also contained in the Paivio, Yuille, and Madigan (1968) norms. All of the pictures chosen were items that could be consistently labeled (80\%-100\% accuracy) and had a short label latency (1.54 sec or less). Sixty abstract nouns were chosen from the Paivio, Yuille, and Madigan (1968) norms; the nouns were equated to the concrete noun labels for word frequency and meaningfulness values but differed significantly in imagery and concreteness scores. Thirty-five-millimeter black and white slides were made of each picture, its word label, and of each abstract noun. The words appeared as block capitals and were approximately the same size as the pictures.

\section{Procedure}

The general procedure used by Erdelyi and Becker (1974) was employed. Subjects were told that, as soon as the room lights were dimmed, they would be shown a series of pictures or words, each item being presented at a 5-sec rate. Subjects were asked to learn these items in preparation for a recall test. They were not told at this time that three successive recall tests were

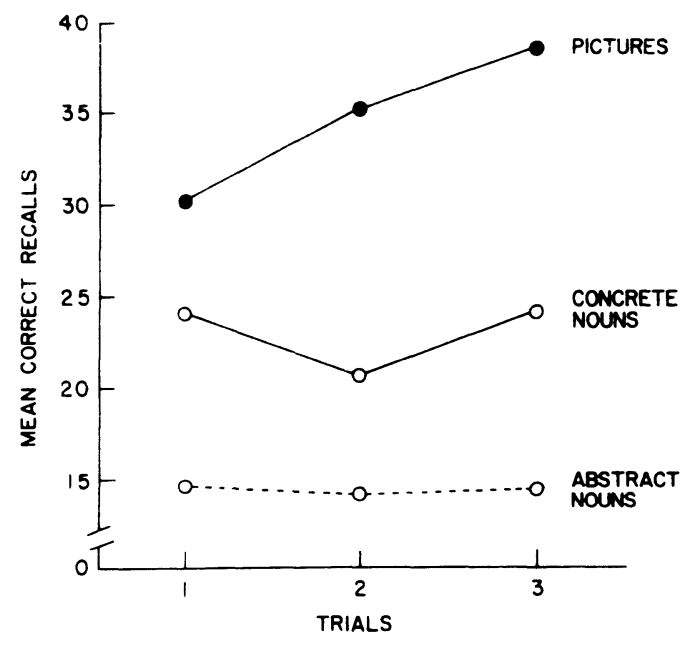
trials.

Figure 1. Mean number of correct recalls over successive to be given. On completion of the learning trial, the room lights were turned on and the instructions for the multiple recall tests were given. Presumably, reading the instructions at this point minimized any recency effects. Subjects recorded their responses in 3-page booklets, each page representing a recall trial. Subjects in the picture group were permitted to use their own labels for pictorial response items, e.g., either "boot" or "shoe" was regarded as a correct response. The verbal label, however, had to be identical over trials to be scored as a correct response. Following the lead of Erdelyi and Becker (1974), a forced recall procedure was used, requiring a fixed number of nonrepeating responses per trial. This control eliminates report criterion differences across subjects and recall trials. Subjects were required to make 40 nonrepeating responses on each trial. This number of responses leaves room for improvement in performance over trials, but does not force subjects to generate an unduly high number of guesses. Subjects were required to respond with a nonrepeating verbal response to each of the 40 lines printed on each page. They were told that, if they should get stuck before reaching the 40th line, they should stop, think, and try to recall some more items, but that if responses were still unavailable, they should make educated guesses. Subjects were given $7 \mathrm{~min}$ to complete each trial. To insure that all 40 responses were attempted, warning signals were given $1 \mathrm{~min}$ and $1 / 2 \mathrm{~min}$ before the end of the 7 -min test period. Prior to the beginning of Recall Trial 2 and Recall Trial 3, the experimenter collected the completed response page. Each test trial was separated by a 7-min retention period, during which subjects were instructed to sit quietly and think about the items that had been presented to them.

\section{RESULTS}

Figure 1 shows the mean number of correct responses for each of the three treatment conditions on each recall trial. A 3 by 3 analysis of variance with Stimulus Groups treated as a between-subjects variable and Trials as a within-subjects variable yielded a highly significant main effect for the three stimulus conditions, $F(2,27)=$ $32.55, \mathrm{p}<.01$. Performance over trials for all three groups did not show a significant change, $\mathrm{F}<1.00$. However, the interaction of Stimulus Groups by Trials was significant, $F(4,54)=2.69, p<.05$. Visual inspection of Figure 1 shows that picture recall increased over trials, while recall for both concrete nouns and abstract nouns was a flat, nonincremental function. Post hoc analyses using the Newman-Keuls test confirmed $(p<.01)$ the overall recall superiority of pictures over concrete words and the superiority of concrete word recall over abstract words.

\section{DISCUSSION}

These results confirm those previously obtained showing an incremental memory for pictures but not for words in multiple recall trials (Erdelyi \& Becker, 1974), and extends these findings to include both concrete nouns and abstract nouns. It is argued in this paper that these results cast doubt upon a dual encoding interpretation to explain differences in learning of simple pictures and their word labels. An alternative explanation, such as qualitative differences in imagery between pictures and their word labels, however, may account for these performance disparities. Titchener (1909) first argued that imagery as meaning is variable and its contents vary in time. In other words, one should expect to find qualitative differences in imagery of concrete stimulus materials which will influence retention. 
The results of this study suggest that the folk wisdom that a picture is worth a thousand words should be modified to state that a picture is worth a thousand images and also may be worth a thousand words. The hypermnesic effect for pictures but not words may be a result of the qualitatively superior images which are made available with repeated probes. Nelson, Reed, and Walling (in pres\$) have offered a similar argument to account for the picture superiority effect. Pictures, in contrast to their word labels, provide a qualitatively superior sensory code. The sensory codes of pictures are more differentiating and less susceptible to interitem interference than are the graphic similarities among words. Nelson et al. (in press) argue that it is the sensory codes of pictures, and not the semantic representations of pictures and their word labels, which account for the performance differences.

The recall superiority of concrete nouns over abstract nouns, however, does support the dual encoding theory. Since both types of nouns were equated for meaningfulness and word frequency, verbal processes alone cannot account for the noun abstractness/concreteness results. Concrete words are more memorable than abstract words because they more readily elicit memory images. This word imagery, however, does not produce a hypermnesic memory function and must be distinguished from the qualitatively superior imaginal representations elicited by pictures.

\section{REFERENCE NOTE}

1. Csapo, K. G. Stimulus attributes, presentation rate, and coding in short-term memory. Unpublished $\mathrm{PhD}$ dissertation, University of Western Ontario, London, Canada, 1971.

\section{REFERENCES}

ERdelyi, M. H., \& BeCKer, J. Hypermnesia for pictures: Incremental memory for pictures but not words in multiple recall trials. Cognitive Psychology, 1974, 6, 159-171.

Nelson, D. L., \& Brooks, D. H. Functional independence of pictures and their verbal memory codes. Journal of Experimental Psychology, 1973, 98, 44-48.

Nelson, D. L., Reed, V., \& Walling, J. R. The pictorial superiority effect. Journal of Experimental Psychology: Human Learning and Memory, in press.

Paivio, A. Imagery and verbal processes. New York: Holt, Rinehart \& Winston, 1971.

Paivio, A., \& Csapo, K. Concrete-image and verbal memory codes. Journal of Experimental Psychology, 1969, 80, 279-285.

PaIvio, A., \& CsAPo, K. Picture superiority in free recall: Imagery or dual coding? Cognitive Psychology, 1973, 5, 176-206.

Paivio, A., Rogers, T. B., \& Smythe, P. C. Why are pictures easier to recall than words? Psychonomic Science, 1968, $11,137-138$.

Paivio, A., Yuille, J. C., \& Madigan, S. Concreteness. imagery, and meaningfulness values for 925 nouns. Journal of Experimental Psychology Monograph Supplement. 1968, 76(1, Part 2).

THORNDIKE, E. L., \& LORGE, I. The teacher's word book of 30,000 words. New York: Bureau of Publications, Teachers College, Columbia University, 1944.

TITCHENER, E. B. Lectures on the experimental psychology of thought processes. New York: Macmillan, 1909.

YARMEY, A. D. Effect of labelling-latency of pictures in associative learning of pictorial representations and their word labels. Canadian Journal of Psychology, 1974, 28, 15-23.

(Received for publication April 18, 1976.) 